\title{
Sol-gel one-pot synthesis in soft conditions of mesoporous silica materials ready for drug delivery system
}

\author{
Corine Tourne-Peteilh $\cdot$ Sylvie Begu $\cdot$ \\ Dan A. Lerner · Anne Galarneau • Ugo Lafont • \\ Jean-Marie Devoisselle
}

Received: 21 October 2011/Accepted: 29 November 2011/Published online: 13 December 2011

(C) Springer Science+Business Media, LLC 2011

\begin{abstract}
The present work reveals a new and simple strategy, a one-step sol-gel procedure, to encapsulate a low water-soluble drug in silica mesostructured microparticles and to improve its release in physiological media. The synthesis of these new materials is based on the efficient solubilisation of a poorly water-soluble drug in surfactant micelles (Tween 80, a pharmaceutical excipient) which act as template for the silica network. A strict control of the sol-gel process and the parameters procedure in soft conditions (concentration, $\mathrm{pH}$, temperature) was applied to reach the solubilisation limit of the drug in the micellar solution so as to optimise its encapsulation. Even if this one-pot procedure could appear limited by the low drug loading, it could provide an interesting alternative for the formulation of many recent highly active but very poorly soluble drugs.
\end{abstract}

Keywords Drug delivery · Sol-gel · Templating · Ibuprofen - Tween 80

Electronic supplementary material The online version of this article (doi:10.1007/s10971-011-2646-x) contains supplementary material, which is available to authorized users.

C. Tourne-Peteilh $(\bowtie) \cdot$ S. Begu $~$ D. A. Lerner .

A. Galarneau · J.-M. Devoisselle Institut Charles Gerhardt Montpellier, UMR 5253 CNRS-UM2ENSCM-UM1, Matériaux Avancés pour la Catalyse et la Santé, 8 rue de l'Ecole Normale, 34296 Montpellier Cedex 5, France

e-mail: tourne@enscm.fr

U. Lafont

Nanostructured Materials, Faculty of Applied Sciences,

Delft University of Technology, Julianalaan 136,

2628 BL Delft, The Netherlands

\section{Introduction}

Formulating poorly water-soluble drugs is of great importance for most known drugs that usually exhibit less than $100 \mu \mathrm{g} \mathrm{mL}^{-1}$ solubility limit [1]. This is a great challenge especially for oral administration. Drug solubilisation in the gastrointestinal tract is a complex process affecting the absorption of the drug, hence its bioavailability. The physical forms also influence the drug solubility, in the range crystalline $<$ amorphous $<$ molecular. Formulation strategies end up combining both the drug form to improve drug solubility and the dosage form to adjust the administration route [2].

Starting around year 2000, studies began to probe the potential of micelle-templated silica materials (MTS) such as MCM-41 or MSU-x, as drug delivery systems (DDS) [3-9]. MTS have received a great deal of interest for their high surface area $\left(1,000 \mathrm{~m}^{2} \mathrm{~g}^{-1}\right)$, their large mesoporous volume $\left(1 \mathrm{~cm}^{3} \mathrm{~g}^{-1}\right)$ and their ordered mesoporous network. Surface and pore size modifications were used to control drug loading (by adsorption or grafting) and release. Confinement effects and interconnectivity of the mesoporous network were also demonstrated to enhance drug solubility in the case of inclusion by adsorption from an organic solution of ibuprofen, a widely used model drug $[5,10,11]$.

There are however several drawbacks with this method that first resorts to a time consuming and costly multistep synthesis procedure (sol-gel MTS process, calcination, potential post-synthesis functionalisation, drug adsorption or grafting). The second one is that an organic solvent is needed to both solubilise the drug and allow adsorption at the solid surface. Now the International Conference on Harmonisation [12] recommend the use of solvents safe as possible (class 3) or with limited residual traces (class 2), for human pharmaceutical applications. 
Inclusion of drugs in porous silica matrices by sol-gel processing in which drug release profiles depend on formulation parameters is known since decades [13-16]. We recently proposed to combine the sol-gel and spray-drying procedures, using self-assembly of surfactant, drug and oxoalkoxide oligomers. The properties of these DDS materials could be easily tuned by changing the synthesis parameters, such as the drug content and surfactant molecules, as well as the chemical nature of the surface of the siloxane network [17]. Nevertheless, the control of the morphological and textural properties of the material required high temperature $\left(\geq 100{ }^{\circ} \mathrm{C}\right.$ ) that could damage the drug.

The present study describes another method to include a poorly water-soluble drug in mesoporous silica matrices by a one-pot process, in soft-conditions of solvent and temperature. In the latter, the drug was first solubilised in surfactant micelles that had two functions: (1) they acted as directing agent for framework assembly; (2) they enhanced the dissolution of the sparingly water-soluble drug and improved its biodisponibility in the release step. Ibuprofen was chosen as a model molecule, in order to compare these results with those of previous studies. Tween 80 was used as a template in the formation of MSU-X materials. Tween 80 is widely used in cosmetics, food products, oral, parenteral and topical pharmaceutical formulations. It was generally regarded as a nontoxic and non-irritant material [LD50 (mouse, oral): $25 \mathrm{~g} \mathrm{~kg}^{-1}$ ] [18]. The as-synthesised hybrid organic-inorganic materials were obtained in soft sol-gel conditions, in a one-pot process that did not involve any organic solvent, a highly desirable feature from a pharmaceutical point of view. The materials obtained were fully characterised and in vitro tests of their properties were then performed in simulated physiological media. The dissolution rate of ibuprofen was shown to be significantly enhanced compared to that of pure drug crystals. The behaviour of these new materials was also compared to that of MCM-41 containing ibuprofen adsorbed from an organic solvent. The results obtained pointed out the advantages and the drawbacks of the method and allowed to correlate the drug release efficiency to the textural properties of the materials.

\section{Experimental}

\subsection{Materials}

Ibuprofen (alpha-methyl-4-[isobutyl]phenylacetic acid) (M = $206 \mathrm{~g} \mathrm{~mol}^{-1}$, $\geq 98 \%$ GC) (Fig. 1), polyoxyethylene sorbitan monooleate with $\mathrm{w}+\mathrm{x}+\mathrm{y}+\mathrm{z}=20$ (Tween 80) $\left(\mathrm{M}=1,320 \mathrm{~g} \mathrm{~mol}^{-1}\right.$, Ultra grade) (Fig. 1), tetraethoxysilane (TEOS, sodium fluoride (NaF) (99\% grade) were purchased from Sigma Aldrich. Tri-distilled water was used for all experiments.

\subsection{Ibuprofen solubilisation in micelles}

Different amounts of ibuprofen were added to a $0.02 \mathrm{M}$ solution of Tween $80(\mathrm{pH} \mathrm{2}$, adjusted with a $30 \mathrm{wt} \% \mathrm{HCl}$ solution) to vary the ibuprofen/Tween 80 molar ratios $\left(\mathrm{R}_{\mathrm{iT}}\right)$ from 0 to 0.4 . Solutions were equilibrated overnight under stirring at ambient temperature $\left(23^{\circ} \mathrm{C}\right)$. The hydrodynamic mean diameter of the resulting micelles was estimated by quasi-elastic light scattering (QELS) using an Autosizer 4800 (Malvern Instruments) equipped with a $532 \mathrm{~nm}$ laser beam $(50 \mathrm{~mW})$. Measurements were done at a $90^{\circ}$ angle and at ambient temperature $\left(23^{\circ} \mathrm{C}\right)$ on samples previously filtered on $0.2 \mu \mathrm{m}$ membranes (Millipore). Samples were observed with an optical microscope equipped with a polarising filter in order to check the presence of ibuprofen crystals.

\subsection{Encapsulation of ibuprofen in MSU-type materials}

The syntheses were carried out at ambient temperature $\left(23{ }^{\circ} \mathrm{C}\right)$ based on a protocol derived from that described by Boissière et al. [19]. Typically $26.2 \mathrm{~g}$ of Tween 80 were dissolved in a $1.0 \mathrm{~L} \mathrm{HCl}$ solution $(\mathrm{pH} \mathrm{2.0)}$, under stirring. About 0.236 or $0.472 \mathrm{~g}$ ibuprofen were added to $0.3 \mathrm{~L}$ of this solution, corresponding to initial $\mathrm{R}_{\mathrm{iT}}$ molar ratios of 0.2 and 0.4 , respectively. After stirring overnight, $10 \mathrm{~g}$ of TEOS were added to these Tween 80 micellar solutions, under magnetic stirring (molar ratio TEOS/Tween $80=8$ ). The mixture was stirred for $30 \mathrm{~min}$ and then left to age overnight in static conditions. $\mathrm{NaF}$ was then added at a molar ratio NaF/TEOS of $4 \mathrm{~mol} \%$ under stirring and the condensation step of silica was left to occur at $37{ }^{\circ} \mathrm{C}$ under gentle magnetic stirring for $36 \mathrm{~h}$. The as-synthesised materials were then filtered, washed with distilled water and dried at $40{ }^{\circ} \mathrm{C}$ under air. A reference material was

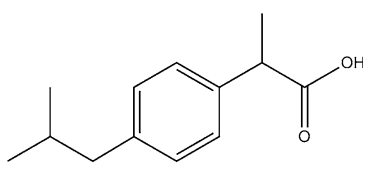

Ibuprofen

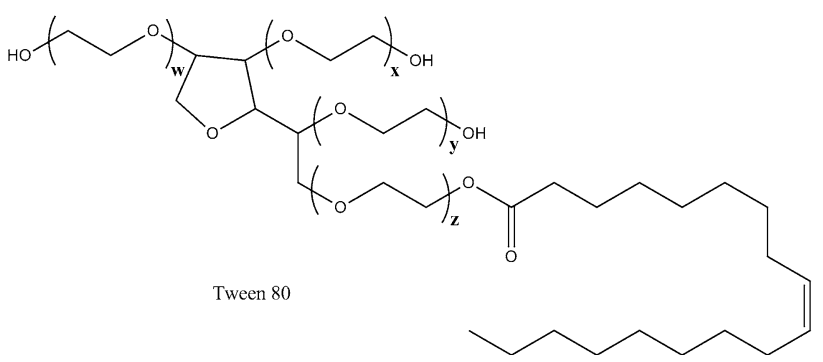

Fig. 1 Chemical formulas of ibuprofen and Tween 80 $(\mathrm{w}+\mathrm{x}+\mathrm{y}+\mathrm{z}=20)$ 
synthesized in the same conditions but without ibuprofen added to the initial micellar solutions. This reference material was named MSU-1. Materials MSU-2 and MSU-3 corresponded to $\mathrm{R}_{\mathrm{iT}}$ molar ratios of 0.2 and 0.4 , respectively.

The amount of encapsulated ibuprofen was determined indirectly, in the aqueous phase recovered after filtration of the material (see below details on the filtration step). In order to obtain textural information the resulting materials were gently and extensively washed in order to extract the organic components (surfactant as well as ibuprofen). The sequence of washings was the following: (1) $1 \mathrm{~h}$ in ethyl acetate/ethanol (1:10), at ambient temperature under magnetic stirring; (2) $1 \mathrm{~h}$ in acetic acid/ethanol (0.5:10), at ambient temperature under magnetic stirring; (3) over night in ethanol, at ambient temperature, under magnetic stirring; (4) over night in a Soxhlet with refluxing ether/dichlorometane (1:1). Afterwards, the samples were dried under vacuum.

\subsection{Material characterizations}

High resolution transmission electron microscopy (HRTEM) was done on a Philips CM30T electron microscope with a LaB6 filament operated at $300 \mathrm{kV}$ as a source of electrons. Samples were mounted on Quantifoil ${ }^{\circledR}$ carbon polymer microgrids supported by a copper grid, placing on the grid a few droplets of a suspension of ground sample in ethanol. Drying was done in ambient conditions. Powder $\mathrm{X}$-ray diffraction (XRD) patterns were recorded on a Brücker Corporation CGR Theta 60 instrument using monochromatic $\mathrm{Cu} \mathrm{K} \alpha 1$ radiation at $\lambda=1.5405 \AA(40 \mathrm{kV}$ and $50 \mathrm{~mA}$ ). The program used to analyse the mesoporous material scanned angles $(2 \theta)$ from $0.7^{\circ}$ to $7^{\circ}$ (step $0.01^{\circ}$, step time $4 \mathrm{~s}$ ). Adsorption/desorption nitrogen isotherms at $77 \mathrm{~K}$ were obtained with a Coulter SA 3100 on calcined samples, previously degassed at $250{ }^{\circ} \mathrm{C}$ for $6 \mathrm{~h}$. Surface areas were calculated with the BET equation used in the pressure range: $0.1<p / p_{0}<0.25$. Pore volumes were determined at the end of the pore filling step at $p / p_{0}=0.6$. Pore mean diameters were determined by using the Broekhoff and de Boer method (BdB) on the desorption branch of the nitrogen isotherm $[20,21]$. Thermogravimetric analyses (TGA) were carried out on a Perkin Elmer TGA 6 under air flow, with a hold of $1 \mathrm{~min}$ at $25^{\circ} \mathrm{C}$ and a temperature increase from 25 to $800{ }^{\circ} \mathrm{C}$ at a rate of $5{ }^{\circ} \mathrm{C}$ $\min ^{-1}$.

\subsection{In vitro dissolution test}

Release of ibuprofen from MSU-2 and MSU-3 samples was performed with a USP Apparatus 4 meant for solid dosage form and supplied with a Sotax flow-through cell
(Dissotest CE 1), according to the standard US Pharmacopeia conditions [22]. Glass microfibers filters, with 2.7 and $1.0 \mu \mathrm{m}$ cut off, have been used at the inlet and outlet of the flow cell, to prevent particle leaching. Release experiments were carried out at $37{ }^{\circ} \mathrm{C}$ at a $4-5 \mathrm{~mL} \mathrm{~min}^{-1}$ flow rate ensuring that the sink conditions were respected (concentration $<10 \%$ of saturation). The simulated gastric medium conditions $(\mathrm{NaCl} 0.03 \mathrm{M}, \mathrm{pH} 1.3)$ were maintained for the first $30 \mathrm{~min}$ after which the medium was changed for a simulated intestinal medium $\left(\mathrm{KH}_{2} \mathrm{PO}_{4}\right.$ $0.05 \mathrm{M}, \mathrm{pH} 7.48$ ) for a period of $120 \mathrm{~min}$ [22]. Aliquots of the release medium were collected at the outlet of the open loop and their content in ibuprofen was determined by HPLC as previously described [5]. The data from the kinetic runs were represented as cumulative percent released ibuprofen over time. They were then averaged for 3 trials run on each MSU-2 and MSU-3. A reference test was carried out with $11 \mathrm{mg}$ of pure ibuprofen crystals in the same conditions as above.

Based on Fickian diffusion, the experimental data points were fitted with a first order model, based on the NoyesWhitney drug dissolution model [23]. It was adapted here to take into account the gastric/intestinal medium switch (Eq. 1, below).

$A_{t} / A_{\infty}=A_{G}+A_{e}\left(1-e^{-K t}\right)$

In Eq. 1, $A_{t}$ was the cumulated amount of drug released at each time $t(\mathrm{~min})$, reported to $A_{\infty}$ the initial drug amount loaded. $A_{e}$ was the maximum amount released at equilibrium. For the simulated intestinal part, the amount of drug released after was added up to $A_{G}$, and $A_{e}$ was the sum of the maximum released in the gastric and the intestinal media. The constant $K\left(\mathrm{~min}^{-1}\right)$ was considered as an apparent diffusion constant.

\section{Results and discussion}

\subsection{Ibuprofen solubilisation in Tween 80 micelles}

Tween 80 (polysorbate 20) is a non-ionic surfactant, commonly used in cosmetic and pharmaceutical formulations to improve the dissolution of poorly water-soluble drugs, by the way of increasing solid dosage form wettability, for example. The Tween 80 solutions were prepared at $\mathrm{pH} 2.0$, below the $\mathrm{pKa}$ of ibuprofen valued at 4.4 , to ensure that the drug was in its non-ionised form and had a low solubility in water. In these conditions, non-ionic Tween 80 micelles have been shown to exert a considerable solubilising effect on weakly acid drugs [24]. It was then expected that ibuprofen would be molecularly taken up by the Tween 80 micelles. 


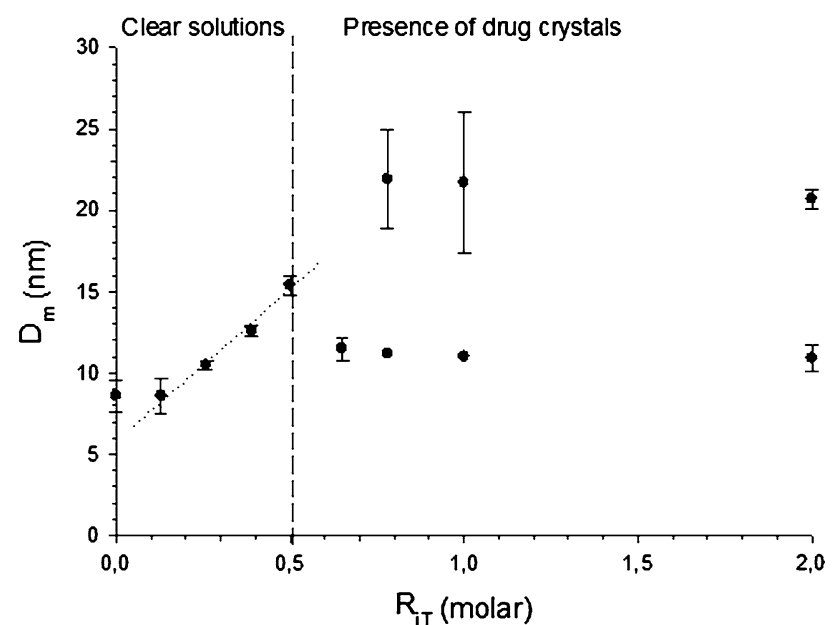

Fig. 2 Evolution of the micellar hydrodynamic mean diameter $\left(D_{m}\right)$ as a function of the molar ratio $\mathrm{R}_{\mathrm{iT}}$-Determination of the solubility limit conditions ( $0.02 \mathrm{M}$ Tween $80, \mathrm{pH} 2)$ (analyses where controlled on 3-5 different solutions)

Changes were observed in the micellar mean hydrodynamic diameter $\left(\mathrm{D}_{\mathrm{m}}\right)$ following solubilisation of the drug (Fig. 2). For values of the ibuprofen/Tween 80 molar ratio, $\mathrm{R}_{\mathrm{iT}}$, in the range $0.1-0.5$, the solutions were clear and $\mathrm{D}_{\mathrm{m}}$ increased linearly from $8.6 \pm 1.1 \mathrm{~nm}$ to $15.4 \pm 0.6 \mathrm{~nm}$ due to the swelling of the micelles.

Hydrogen bonding between the carboxylic group of ibuprofen and the ether oxygen of PEO were probably the main driving force in that solubilisation by Tween 80 micelles [25]. So the drug was expected to be located close to the region bordering the hydrophilic PEO shell and the hydrophobic alkyl core of the micelles. In support to this hypothesis, the solubilisation of benzoic acid derivatives esterified has previously been shown to result in an equilibrium distribution that was shifted between the hydrophilic shell and the hydrophobic core of polyoxyethylene stearate micelles depending on the hydrophilic/lipophilic balance (HLB) of the acid [26]. In that series, the distribution was well correlated with the HLB: derivatives of benzoic acid with polar groups had a greater solubility in the PEO shell while esterification of these compounds shifted the maximum of the distribution towards the hydrophobic core.

For $\mathrm{R}_{\mathrm{iT}}>0.5$, solutions became turbid and drug crystals were observed by polarisation microscopy. Two sets of light scattering objects were detected (Fig. 2), one corresponding to the swollen micelles (clear solutions) and the second to small ibuprofen crystals. In these conditions, the maximum solubility of the drug was obtained at this molar ratio of 0.5 .

Following that preliminary study, MSU-type materials were prepared using $R_{i T}$ values in the range 0.1-0.5. This would insure that ibuprofen would be solubilised in micelles as molecularly dispersed species to later improve its release from the mesoporous materials. The micelles used as templates to prepare three organic-inorganic mesoporous materials labelled MSU-1, MSU-2 and MSU-3, had $D_{m}$ values of $9.4,10.3$ and $14.4 \mathrm{~nm}$ for $R_{i T}=0,0.2$ and 0.4 , respectively (Table 1 ).

\subsection{Characterisation of the templated "MSU-type" materials}

HRTEM characterisation (Fig. 3) was performed on the assynthesised materials, in order to visualise the evolution of the mesostructure as a function of the ibuprofen loading. Ibuprofen free MSU-1 (without ibuprofen) clearly showed a very well defined hexagonal arrangement with a long range order. For MSU-2 $\left(\mathrm{R}_{\mathrm{iT}}=0.2\right)$, the very well defined hexagonal mesostructure was still present when examined at different orientations and the long range ordered texture could be observed as well.

MSU-3 $\left(R_{\mathrm{iT}}=0.4\right)$ was still mesoporous and revealed some long range order, corresponding this time to a regular worm-like structure.

The XRD pattern of all as-synthesised samples showed a $\mathrm{d}_{100}$ scattering peak corresponding to the correlation distance for small mesopores (Fig 4). The peak broadened and lost intensity as $\mathrm{R}_{\mathrm{iT}}$ increased revealing a lowering in the network uniformity. The secondary scattering peaks $d_{110}$ and $d_{200}$ were not observed as could be expected from the HRTEM data. This is certainly due to the loss of diffraction contrast when organic species are filling the pores. Organics were then gently removed to prevent the network constriction usually observed following calcination. In these conditions, lines $d_{100}, d_{110}$ and $d_{200}$ were detected on the extracted samples and the correlation distances associated to these peaks were found to be characteristic of a hexagonal array (see Online Resource, ESM 1).
Table 1 Micelles mean diameter $\left(\mathrm{D}_{\mathrm{m}}\right)$ and textural parameters of the as-synthesised samples as a function of the ibuprofen/Tween $80\left(\mathrm{R}_{\mathrm{iT}}\right)$ molar ratio

\begin{tabular}{|c|c|c|c|c|c|c|}
\hline \multirow[t]{2}{*}{ Material } & \multirow{2}{*}{$\begin{array}{l}\text { Molar } \\
\text { ratio } \\
\mathrm{R}_{\mathrm{iT}}\end{array}$} & \multirow{2}{*}{$\begin{array}{l}\text { Micelles } \\
\text { size } \\
D_{m}(n m)\end{array}$} & \multirow{2}{*}{$\begin{array}{l}\text { As-synthesised } \\
\text { materials } \\
d_{100}(n m)\end{array}$} & \multicolumn{2}{|c|}{ Extracted materials } & \multirow{2}{*}{$\begin{array}{l}\text { After release test } \\
\mathrm{d}_{100}(\mathrm{~nm})\end{array}$} \\
\hline & & & & $\mathrm{d}_{100}(\mathrm{~nm})$ & $\mathrm{D}_{\mathrm{BdB}}(\mathrm{nm})$ & \\
\hline MSU-1 & - & 9.4 & 5.8 & 5.9 & 4.7 & - \\
\hline MSU-2 & 0.2 & 10.3 & 6.0 & 5.7 & 4.7 & 5.3 \\
\hline MSU-3 & 0.4 & 14.4 & 6.3 & 6.3 & 4.6 & 5.6 \\
\hline
\end{tabular}



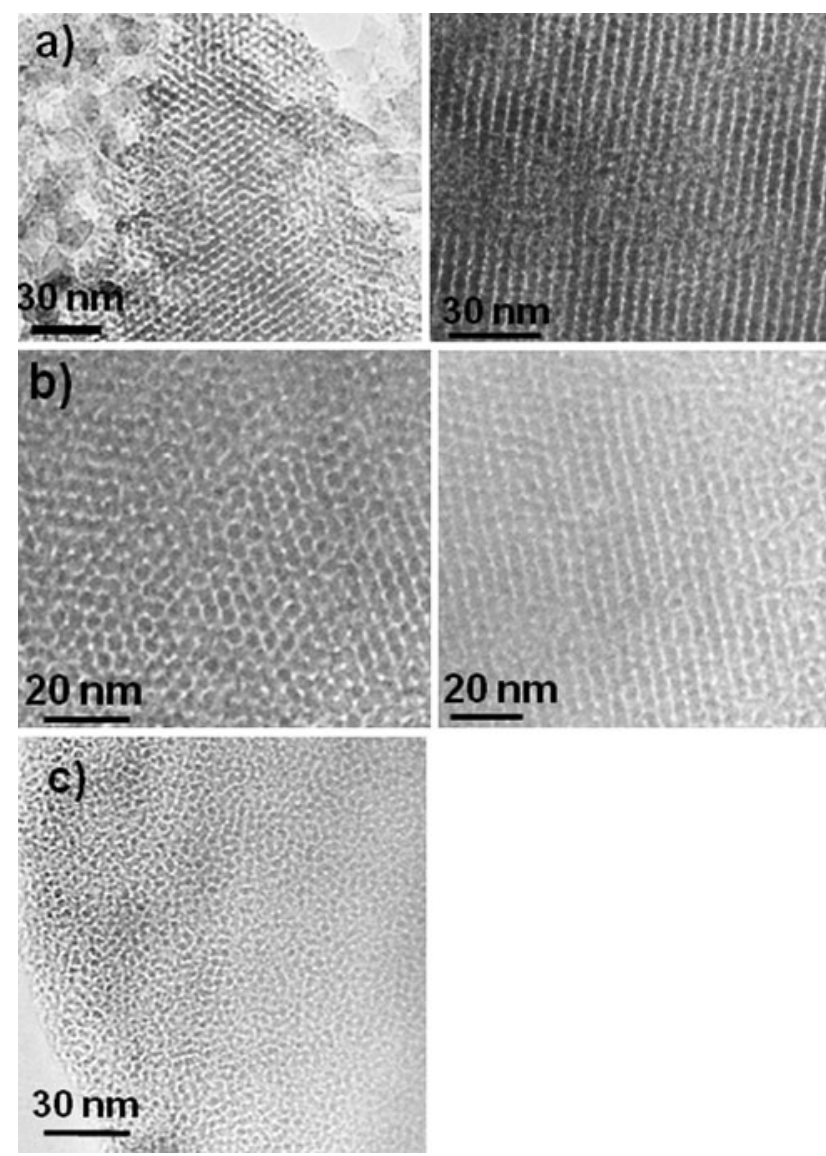

Fig. 3 HRTEM views of as-synthesised particles (a) MSU-1 (without ibuprofen), (b) MSU-2 $\left(\mathrm{R}_{\mathrm{iT}}=0.2\right)$ and (c) MSU-3 $\left(\mathrm{R}_{\mathrm{iT}}=0.4\right)$

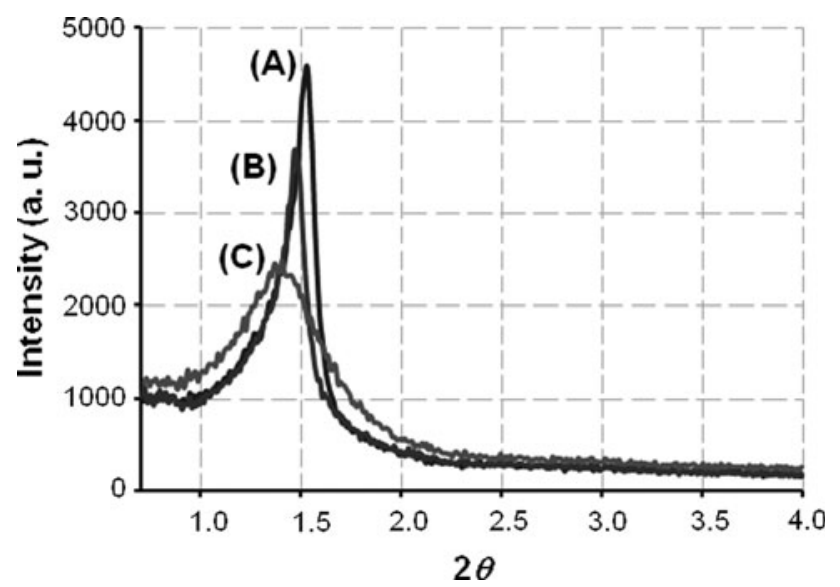

Fig. 4 XRD patterns of the as-synthesised samples (a) MSU-1 (without ibuprofen), (b) MSU-2 $\left(\mathrm{R}_{\mathrm{iT}}=0.2\right)$ and (c) MSU-3 $\left(\mathrm{R}_{\mathrm{iT}}=0.4\right)$

The $\mathrm{d}_{100}$ correlation distances of the as-synthesed materials were compared to $\mathrm{D}_{\mathrm{m}}$. They were found to be smaller than the micelles $\mathrm{D}_{\mathrm{m}}$ (Table 1). This suggested first a close interaction between the PEO head groups and the silica walls.
The latter was confirmed by TG analyses done after the organic extraction process, which revealed a residual weight loss of about $20 \%$ (in the range $100-500{ }^{\circ} \mathrm{C}$ ) ascribed to organics remaining trapped inside the silica walls in spite of efficient washing conditions (see Online Resource, ESM 2). Second, the values found indicated that the pore diameter was mainly defined by the Tween 80 alkyl chain length. An estimate of the maximum diameter of the pores expected from the doubling of the octadecyl chain length came close to $4.3 \mathrm{~nm}$ (chain bent in its centre due to the presence of a cis double bond), a value close to the $\mathrm{D}_{\mathrm{BdB}}$ determined by nitrogen adsorption on washed materials (see Online Resource, ESM 3). The $D_{B d B}$ values (Table 1) for the 3 samples were close to $4.7 \mathrm{~nm}$.

As seen above, increasing the amount of molecularly solubilised ibuprofen in these micelles had a swelling effect. As the solubilised drug was expected to interact mainly with the hydrophilic shell, the increase in $d_{100}$ should be correlated to some extent with that drug loading.

The drug stability was monitored by reverse phase liquid chromatography (see Online Resource, ESM 4). No evidence of ibuprofen degradation was observed during the whole process, from the drug solubilisation in the micelles up to the drug release tests. These results confirmed the drug protection afforded by the soft conditions (solvent, $\mathrm{pH}$ and temperature) chosen for its encapsulation in the MTS material.

\subsection{In vitro dissolution test}

The in vitro release tests were done in simulated oral administration conditions to mimic the gastro-intestinal route characterized by a $\mathrm{pH}$ of 1.3 for the stomach and 7.48 for the intestinal fluids (Fig. 5).

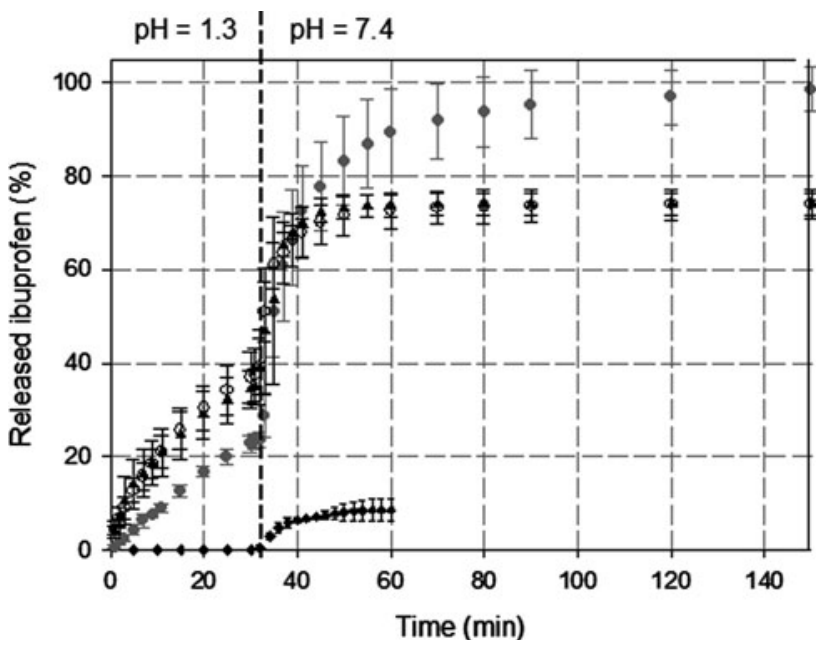

Fig. 5 Kinetic release profiles of ibuprofen in the simulated gastric $(\mathrm{pH}$ 1.3) and intestinal ( $\mathrm{pH}$ 7.4) media of pure ibuprofen crystals (diamond), from MSU-2 (triangle), from MSU-3 (open circle), and from adsorbed MCM-41 (filled circle) $(\mathrm{n}=3)$ 
The release kinetic profiles, expressed as the percentage of ibuprofen present in MSU-2 or MSU-3 were similar for both materials. After $30 \mathrm{~min}$ in the simulated gastric fluid, $35 \%$ of the ibuprofen was released. After switching to the simulated intestinal fluid, the release of ibuprofen increased strongly for $15 \mathrm{~min}$. A plateau was then reached after $50 \mathrm{~min}$, corresponding to an overall $75 \%$ release of ibuprofen.

The release kinetics from MSU-2 and MSU-3 were clearly faster and more efficient than the solubilisation of ibuprofen crystals. For the latter test, no molecular ibuprofen could be detected in the gastric medium at $\mathrm{pH} \mathrm{1.3,}$ while at $\mathrm{pH} 7.4$ the maximum amount detected correspond to a plateau at only an $8 \%$ release.

In the case of MSU-materials, the release mechanisms were mainly driven by Fickian diffusion. The apparent diffusion constant, $K$, increased significantly, from 0.088 to 0.21 , after the $\mathrm{pH}$ switch, while the maximum amount released at equilibrium, $A_{e}$, remained constant (see Eq. 1). So the release mechanism was more sensitive to $\mathrm{pH}$ and/or material modifications and pointed to a modification of the interactions between ibuprofen and the matrix (Table 2). These results have been compared to those obtained with MCM-41 previously published by Charnay et al. [5]. In the case of MCM-41, $K$ was constant indicating that the diffusion mechanism was the same along the entire test and was not affected by the change in the dissolution medium. $A_{e}$ increased significantly at $\mathrm{pH}=7.4$ due to a better ibuprofen solubility above its $\mathrm{pK}$ value. In the end, $A_{e}$ was close to $100 \%$, indicating that there was no barrier to control the diffusion process. It is noteworthy that MCM41 exhibited an excellent stability of the inorganic network after being in contact with the simulated media for at least $24 \mathrm{~h}$.

Post kinetics analyses were made to evaluate changes in the material associated to the release process. TG analyses showed a differential weight loss of $7 \%$, in the range 100-500 ${ }^{\circ} \mathrm{C}$, for MSU-2 and MSU-3 (see ESI 2). The expected weight loss attributed to ibuprofen should be $<1 \%$ (25\% of the initial ibuprofen amount not released).
Then, the weight loss of $6 \%$ should be attributed to released surfactant. The latter observation indicated strong surfactant interactions with the material as described for the as-synthesized material.

The corresponding DRX data revealed a clear decrease of the correlation distance $\mathrm{d}_{100}$ when compared to those of the as-synthesised samples (Table 1). For MSU-2 and MSU-3, a significant weight loss above $450{ }^{\circ} \mathrm{C}(15 \% \mathrm{wt}$ loss) was attributed to a deshydroxylation process. It was due to a degradation of the siloxane network driven by the contact with the simulated physiological media and resulted in the shrinking of the silica framework [27, 28].

Although Fickian diffusion is involved in both MSU and MCM-41, the release mechanism involved different interactions for these mesoporous materials.

For ibuprofen adsorbed in calcined MCM-41, it was shown that the loaded drug underwent a confinement effect that decreased the solid/liquid transition temperature [5, 10]. This effect certainly contributed to the observed enhancement of the drug release rate versus that of pure crystals drug.

When ibuprofen was first solubilised in Tween 80 micelles, which were then used to template the silicate species, there was a marked change in the drug environment. Moreover, attempts to extract all the surfactant present in the new material failed and the maximum amount of drug released in simulated media was about $75 \%$. So diffusion of a large fraction of the drug was facilitated by the presence of the PEO components of the polyethoxylated detergent which were heavily hydrated. However a second population seemed to be irreversibly trapped in the silica walls due to strong interactions between PEO chains and siloxanes during the sol-gel process, as a result of the drug repartition in the initial micelles [25], and could be not release at all. A schematic attempt to illustrate a possible ibuprofen distribution in the materials is displayed in Fig. 6. It takes into account the micelles size, the DRX data of as-synthesised material, BET data on washed samples and release data. PEO hydrophilic chains penetrate into the silica walls,

Table 2 Calculated kinetic parameters

\begin{tabular}{lllllll}
\hline Simulated media & Sample & $A_{G}(\%)$ & $A_{e}(\%)$ & $A_{\max } *(\%)$ & $K\left(\mathrm{~min}^{-1}\right)$ \\
\hline Gastric & Ibuprofen & N.d. & N.d. & N.d. & N.d. \\
& MSU 2, 3 & - & - & 36 & 0.088 & N.d. \\
& MCM-41 & - & - & 79 & 0.985 \\
Intestinal & Ibuprofen & 0 & 9.5 & 9.5 & 0.114 & 0.12 \\
& MSU 2, 3 & 33 & 41 & 998 & 0.21 \\
& MCM-41 & 19 & 75 & 94 & 0.12 & 0.990 \\
& & & & & & 0.985 \\
\hline
\end{tabular}

$* A_{\max }=A_{e}$ in the simulated gastric medium; N.d. = no dissolution have been observed; See Online Resource, ESM 5 for calculation details 
Fig. 6 Schematic representation of the organisation of the MSUmaterials loaded with ibuprofen

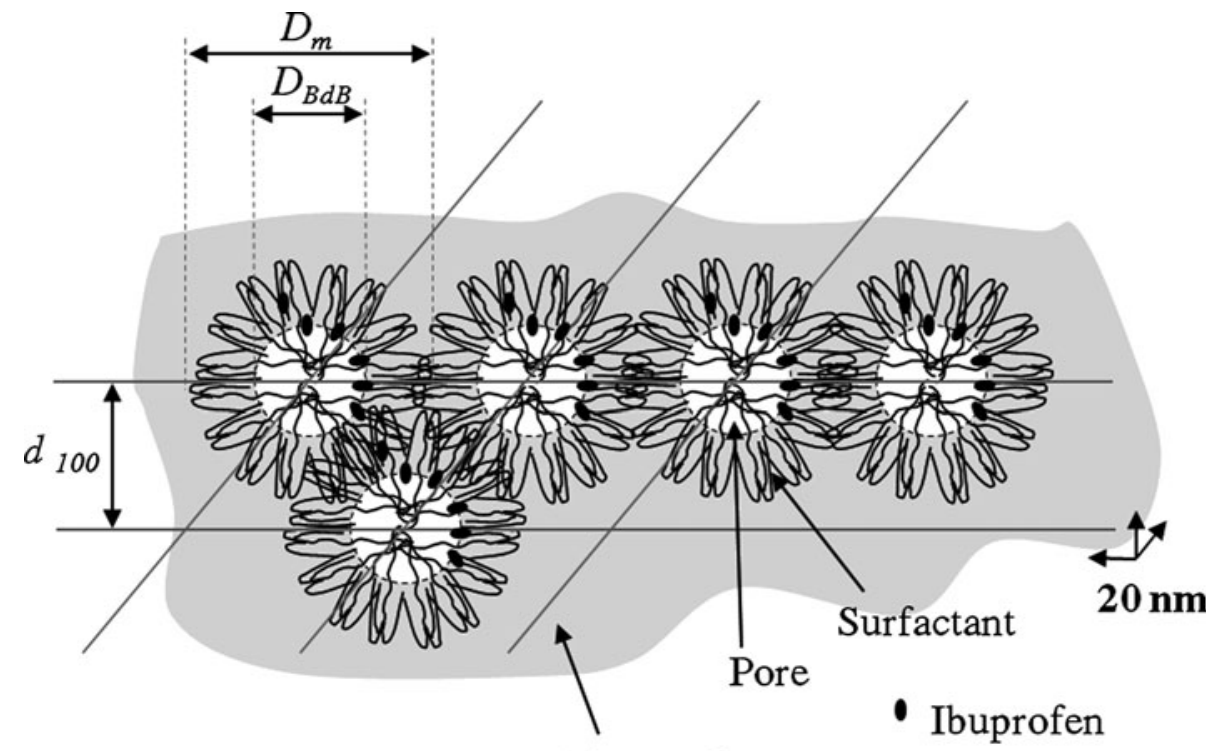

Silica wall explaining that $\mathrm{d}_{100}<\mathrm{D}_{\mathrm{m}}$. The pore diameter $\mathrm{D}_{\mathrm{BdB}}$ is generated by the alkyl chains length. About $75 \%$ of ibuprofen is easily accessible by the dissolution medium and diffuse freely away from the silica network, whereas the remaining $25 \%$ are trapped inside the silica wall with the PEO chains. Finally, MSU-materials appeared to be affected by the contact with the dissolution media that induced modifications of their inorganic framework that in turn hindered the full release of the drug (see Table 1).

\section{Conclusions}

The present work described silica based composite materials constituting a new type of solid pharmaceutical formulation that avoided the use of organic solvent, reduced the number of steps in the process and took account of raw material. These materials were obtained in a one step room temperature sol-gel process involving templating micelles that had first solubilised a poorly soluble drug in an aqueous medium and led to the synthesis of well ordered materials. Tween 80 , a widely used surfactant in pharmaceutical and food formulation, was chosen to form the silica templating micelles.

This study was an attempt to combine the microencapsulation of a poorly water-soluble drug in micelles, and their encapsulation in a MTS material by a sol-gel process, in soft conditions of $\mathrm{pH}$ and temperature without organic solvent.

Even if the drug loading appeared to be less efficient than adsorption from an organic solvent in calcined materials, it should fit the requirements of very poorly soluble drugs, active at low dose (such as the majority of anticancer drugs).

The drug release mechanism is obviously dependent on its complex interactions with the hybrid organic/inorganic matrix. Optimisation in the choice of the surfactant will be a key to fine tune the drug loading as well as the drug release and the interactions with the silica walls.

\section{References}

1. Hörter D, Dressman JB (2010) Influence of physicochemical properties on dissolution of drugs in the gastrointestinal tract. Adv Drug Del Rev 46:75-87

2. Liu R (2008) Water-insoluble drug formulation. Taylor \& Francis, Boca Raton

3. Aiello R, Cavallaro G, Giammona G, Pasqua L, Pierro P, Testa F (2002) Mesoporous silicate as matrix for drug delivery systems of non-steroidal anti-inflammatory drugs. Stud Surf Sci Catal 142:1165-1172

4. Anderson J, Rosenholm J, Areva S, Linden M (2004) Influences of material characteristics on ibuprofen drug loading and release profiles from ordered micro- and mesoporous silica matrices. Chem Mater 16:4160-4167

5. Charnay C, Begu S, Tourne-Peteilh C, Nicole L, Lerner DA, Devoisselle J-M (2004) Inclusion of ibuprofen in mesoporous templated silica: drug loading and release property. Eur J Pharm Biopharm 57:533-540

6. Tourne-Peteilh C, Brunel D, Begu S, Chiche B, Fajula F, Lerner DA, Devoisselle J-M (2003) Synthesis and characterisation of ibuprofen-anchored MCM-41 silica and silica gel. New J Chem 3:281-286

7. Tourne-Peteilh C, Lerner DA, Charnay C, Nicole L, Bégu S, Devoisselle J-M (2003) The potential of ordered mesoporous for the storage of drugs : the example of a pentapeptide encapsulated in a MSU-Tween 80. Chem Phys Chem 3:281-286 
8. Vallet-Regi M, Ramila A, del Real RP, Perez-Pariente J (2001) A new property of MCM-41: drug delivery system. Chem Mater 13:308-311

9. Vallet-Regi M, Balas F, Colilla M, Manzano M (2007) Bioceramics and pharmaceuticals: a remarkable synergy. Solid State Sci 9:768-776

10. Azaïs T, Tourné-Péteilh C, Aussenac F, Baccile N, Coelho C, Devoisselle J-M, Babonneau F (2006) Solid-state NMR study of ibuprofen confined in MCM-41 material. Chem Mater 18: 6382-6390

11. Heikkilä T, Salonen J, Tuura J, Hamdy MS, Mul G, Kumar N, Salmi T, Murzin DY, Laitinen L, Kaukonen AM, Hirvonen J, Lehto V-P (2007) Mesoporous silica material TUD-1 as a drug delivery system. Int J Pharm 331:133-138

12. Impurities: guideline for residual solvents (2009) In London-UK, European Medicines Agency, 22

13. Unger K, Rupprecht H, Valentin B, Kircher W (1983) The use of porous and surface modified silicas as drug delivery and stabilizing agents. Drug Dev Ind Pharm 9:69-91

14. Kortesuo P, Ahola M, Karlsson S, Kangasniemi I, Yli-Urpo A, Kiesvaara J (2000) Silica xerogel as an implantable carrier for controlled drug delivery-evaluation of drug distribution and tissue effects after implantation. Biomaterials 21:193-198

15. Kortesuo P, Ahola M, Kangas M, Kangasniemi I, Yli-Urpo A, Kiesvaara J (2000) In vitro evaluation of sol-gel processed spray dried sillica gel microsphères as carrier in controlled drug delivery. Int J Pharm 200:223-229

16. Ahola M, Säilynoja E, Raitavuo M, Vaahtio M, Salonen J, YliUrpo A (2001) In vitro release of heparin from silica xerogels. Biomaterials 22:2163-2170

17. Fatnassi M, Tourne-Peteilh $\mathrm{C}$, Cacciaguerra $\mathrm{T}$, Dieudonné $\mathrm{P}$, Devoisselle J-M, Alonso B (2010) Tuning nanophase separation and drug delivery kinetics through spray drying and self-assembly. New J Chem 34:607-610

18. Rowe RC, Sheskey PJ, Owen SC (2006) Handbook of pharmaceutical excipients, 5th edn., Pharmaceutical Press, London

19. Boissière C, Larbot A, Van der Lee A, Kooyman PJ, Prouzet E (2000) A new synthesis of mesoporous MSU-X silica controlled by a two-step pathway. Chem Mater 12:2902-2913

20. Broekhoff JCP, de Boer JH (1968) Studies on pore systems in catalysts-chap. XIII. J Catal 10:377-390

21. Galarneau A, Desplantier D, Dutartre R, Di Renzo F (1999) Micelle-templated silicates as a test bed for methods of mesopore size evaluation. Microporous Mesoporous Mater 27:297-308

22. US Pharmacopeia and national formulary (1999)

23. Costa P, Sousa Lobo JM (2001) Modeling and comparison of dissolution profiles. Eur J Pharm Biopharm 13:123-133

24. Gerakis AM, Koupparis MA, Efstathiou CE (1993) Micellar acidbase potentiometric titrations of weak acidic and/or insoluble drugs. J Pharm Biomed Anal 11:33-41

25. Schachter DM, Xiong J, Tirol GC (2004) Solid state NMR perspective of drug-polymer solid solutions: a model system based on poly (ethylene oxide). Int J Pharm 281:89-101

26. Attwood D, Florence AT (1985) Surfactant systems-their chemistry, pharmacy and biology, 2nd edn. Chapman and Hall, London

27. Bass JD, Grosso D, Boissiere C, Belamie E, Coradin T, Sanchez C (2007) Stability of mesoporous oxide and mixed metal oxide materials under biologically relevant conditions. Chem Mater 19:4349-4356

28. Begu S, Aubert Pouëssel A, Lerner DA, Tourne-Peteilh C, Devoisselle J-M (2007) Liposil, a promising composite material for drug storage and release. J Control Release 118:1-6 